\title{
Monitoring and Controlling The Hybrid System Using The Internet Of Things For Energy Transaction
}

\author{
Sulton Ari Wibowo ${ }^{1}$, Dyah Lestari ${ }^{2}$
}

\author{
Authors \\ ${ }^{1}$ Universitas Negeri Malang, Malang 65145, Indonesia, \\ sultonariwibowo66@gmail.com \\ ${ }^{2}$ Universitas Negeri Malang, Malang 65145, Indonesia, \\ dyah.lestari.ft@um.ac.id \\ Corresponding: sultonariwibowo66@gmail.com
}

\begin{abstract}
The electrical energy is an energy that is needed by the people. The electrical energy, to date, came from several power plants, such as electric steam power plants and diesel power plants. The community must pay the service provider, such as the State Electricity Company (PLN) with a rising cost, to obtain electrical energy. However, there were other alternative energies, for example, solar power plants and windmill power plants. The hybrid system is a combination of two or more different energy sources to meet the demand. The hybrid system was also expected to solve the problem that might arise in utilizing other energies, the site condition, and the unpredicted situation on the power plant. The solution to these problems was a hybrid using a monitoring device with ACS 712 sensor current parameter, ZMPT101B voltage sensor, LDR solar sensor, hybrid electrical energy power, controller for four electrical source inputs and three electrical sources for the output load. The device used Arduino Mega 2560 for data processing, ESP 8266 as the module to connect the device to the internet network and relay as the control actuator. Monitoring and controlling the device used the internet network and the implementation of the Internet of Things (IoT) on the hybrid system plants (PLN, generator, solar power plant, windmill power plant) that was integrated into the website. The overall test resulted in the comparison average error value between the device and the measuring instrument of the current, voltage, and power. The test also resulted in the average error value of the response time for the four input contacts and three output contacts. The average error value of the current was $2.13 \%$, the average error value of the voltage was $0.7 \%$, and the average error value from the power parameter was $0 \%$. Meanwhile, the average error value of response time was 0.23 seconds. Based on the above results, it can be concluded that the monitoring and controlling system from the website with the implementation of the IoT in the hybrid power system was worked following the design.
\end{abstract}

Keywords

Internet of Things, Hybrid Power Systems, Control, Monitoring,

ESP8266, Website Monitoring and Control

\section{Introduction}

Electrical energy is an energy that people need. All devices that use electronic components required electrical energy to operate be it in the industry or around us. Nowadays, we use electrical energy from power plants, such as water power plants and diesel power plants. Renewable energy sources are environmentally friendly and do not contribute towards the climate change and global warming because it comes from the sustainable natural process, for example, the sun, wind, water, biofuel, and geothermal [1]-[3]. The hybrid system is a combination concept from two or more different energies to meet the required demand. The hybrid system was expected to support the resolution of energy usage if there is a problem in utilizing other energies.

The research of the hybrid power system used conventional monitoring and controlling. Moreover, manual monitoring has resulted in a limited, unsustainable, and incomplete parameter and data monitoring. Besides, local operator observation was at a disadvantage because of the distributed plant units in different locations. Centered monitoring and controlling with long-distance communication was needed to support the observation and controlling the hybrid plant, considering the time and place. The previous researches have discussed the web-based monitoring system application to monitor electrical energy [4]-[8]. These researches have designed the monitoring system that was used on the photovoltaic system based on the Internet of Things (IoT) using a wireless node. Based on the above problems, centered long-distance monitoring and controlling could be further researched to obtain a solution. Therefore, this research studied the "Implementation of the Internet of Things for Monitoring and Controlling the Hybrid System." 


\section{Literature Review}

\subsection{Electrical Energy Source}

The local and potential sources for electrical energy are solar energy, wind energy, and micro-hydro energy. Using the local renewable energies would ensure their availability for power plants. Using renewable energies, apart from their potentials, also decreases the dependency on fuel [1], [2].

\subsection{Hybrid}

Hybrid is an electrical power plant that combines more than one technology. Hybrid on this research referred to one energy or a combination of four electrical energy sources such as solar power plant, windmill power plant, State Electricity Company, and generator set.

\subsection{ACS 712 Current Sensor}

ACS 712 current sensor is a sensor to detect the amount of the current. The ACS 712 has hall effect technology put by Allegro company to replace the resistor and current transformation into a sensor to measure the current. The hall effect term became famous after Edwin H. Hall (1855-1938) found that if an electric current flow through a conductor at the latitude of a strong magnetic field, it would produce a potential difference that passed through the conductor at both conductor angles. The hall effect sensor is a transducer that could change the amount of magnetical field into the electrical field in the form of current. This type of sensor in its operation detect proximity, the existence or the absence of a magnetic field from an object [9][11].

\subsection{ZMPT 101B Current Sensor}

ZMPT101B sensor is a sensor to monitor the voltage parameter that excels in its ultra micro voltage transformer, high accuracy, and excellent consistency in measuring voltage and power.

\subsection{LDR Light Sensor}

The light-dependent resistor (LDR) light sensor is a type of resistor that can change its resistance if the light reception changes. The value depends on the light reception of the sensor. The LDR resistance in a dark place could reach up to $10 \mathrm{Mohm}$ and in a light place decreases into around $150 \mathrm{ohms}$. Its characteristic is a component that the resistance change depends on the light.

\subsection{Arduino Mega 2560}

Arduino Mega 2560 is a microcontroller device that uses Atmega 2560. This module has 54 digital inputs or outputs where 14 pins are used for PWM output, 16 pins for analog input, four pins for UART, $16 \mathrm{MHz}$ crystal oscillator, a USB connection, a power jack, an ICSP header, and a reset button. This module has some tools to program the microcontroller such as USB cable and power supply through an adaptor or battery. The devices act as supporters for the Arduino microcontroller.

\subsection{ESP 8266}

The ESP 8266 module is a wifi module with full support on TCP/IP. China-based developer, Espreffit, developed ESP 8266 in many variants with ESP 012 series was used in this research. This wifi module is a System on Chip (SoC) to conduct direct programming into the ESP 8266 without an additional microcontroller [12], [13]. The ESP 8266 module also has an unrivaled ability to embed WiFi capabilities in other systems or function as a standalone application with low costs and minimal space requirements.

\subsection{Arduino Nano}

Arduino nano is a microcontroller board based on Atmega 328. It has 14 pins for digital input/output (6 as the PWM output), six analog inputs, a $16 \mathrm{MHz}$ crystal oscillator, a USB connection, a power jack, an ICSP header, and a reset button. Arduino Nano included anything to support the microcontroller using the USB cable or supplying it with AC-DC adaptor or battery.

\subsection{Relay}

A relay is a switch that operates electrically. It is an electromechanical component that consists of two main points: electromagnet (coil) and mechanical (a set of switches). Relay uses the electromagnetic principle to move the switch so that low power electrical current could conduct electricity with higher voltage.

\subsection{The Internet of Things}

The initial idea of the IoT by Kevin Ashton in 1999 was that the objects around humans could communicate one another through a connection such as using the internet. Started from the Auto-ID Center, a technology that was based on the Radio Frequency Identification (RFID) that was an identification of a unique electronic product code which was then developed into a technology of which every object can have an 
Internet Protocol (IP) address. The development of internet infrastructure, the next stage was not only about the smartphone or computer that could be connected to the internet, but also many real objects. The objects that are all connected to local and global networks using embedded sensors and or actuators [14].

\section{Research Method}

Figure 1 shows the design stages of the device.

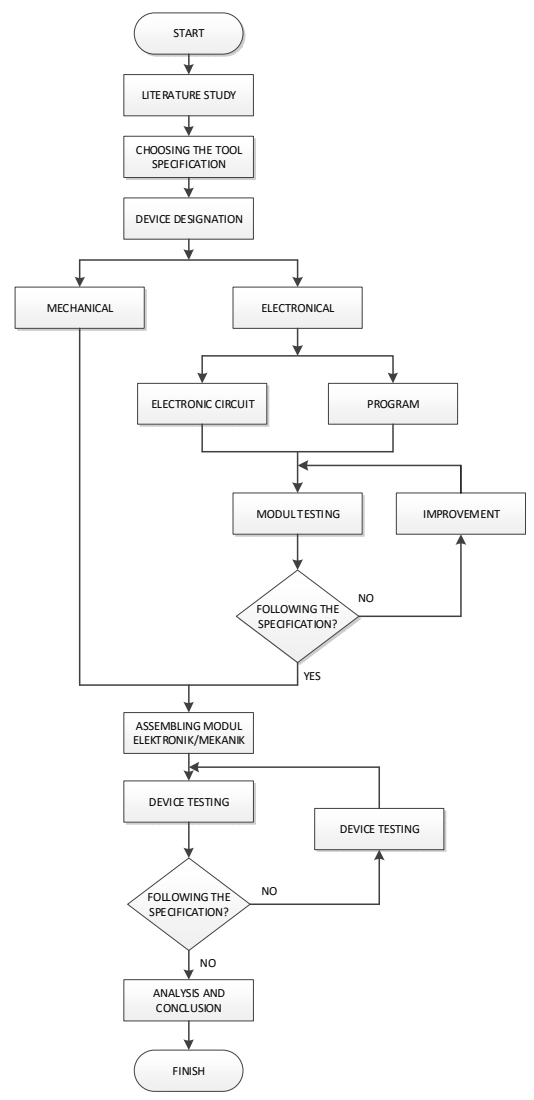

3.1 System Designation

Figure 1. Tool Design Flowchart

System designation was conducted as the first step before the formation of a system and its supporting electronic circuits that the system can identify and run as planned.

System designation covered:

- Determination of inputs, processes, and outputs used as

$>$ Input

Current sensor : ACS 712

Voltage sensor : ZMPT101B AC and DC

Light sensor : LDR (light dependent resistor)

Process

Processing : : Arduino Mega2560, Arduino Nano dan ESP8266

$>$ Output

Plan : Relay

$>$ Communication

Radiofrequency: NRF2401

- Program design on the Arduino Mega 2560 microcontroller, Arduino Nano and ESP8266 as the central control system.

- Communication design using the radio with NRF2401 frequency.

- Design programs for monitoring systems and regulating restrictions on the use of electric current

\subsection{Device Designation}

3.2.1 Device on PV (Photovoltaic)

The device shows that the data 1 that was assumed as the electrical source data from the photovoltaic (PV) in the forms of current and voltage. There were also three inputs as sensors, one of which was the light 
sensor to detect the sunray, ACS712 sensor as the current sensor, and ZMPT101B sensor as the current sensor. There was also Arduino Nano as the component of data processing readings from three sensors and NFR2401+ as the long-distance communication media to send the processing data from the microcontroller to the main device.

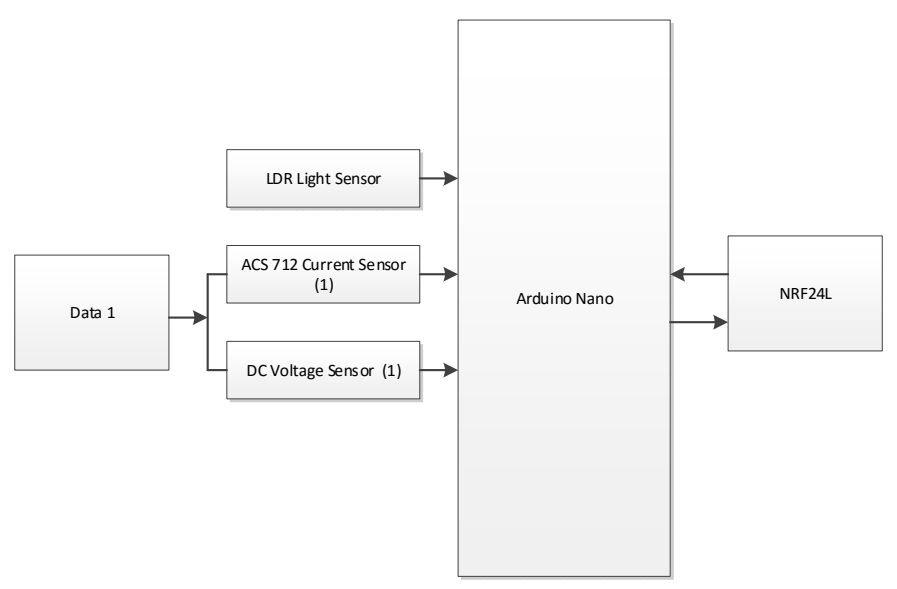

Figure 2. PV Device

\subsubsection{The device on Wind Turbin}

The data 2 was assumed as the data from the wind turbine electrical source with rotary encoder sensor that acted as the speed detection sensor from the turbine rotation. There was also the ACS712 sensor as the current sensor and ZMPT101B sensor as the voltage sensor. There was also the Arduino Nano as the component of data processing readings from three sensors and NFR2401+ as the long-distance communication media to send the processing data from the microcontroller to the main device.

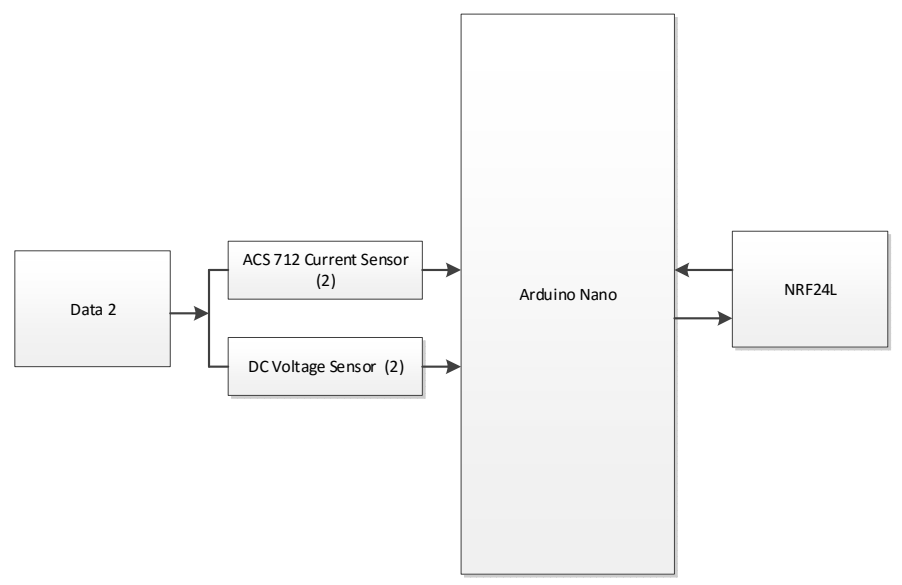

Figure 3. Wind Turbine Device

\subsubsection{The Main Device}

The block diagram in Figure 4 represents the main block from the designated system. Several blocks function as below. Data block three and data block four was assumed as the State Electricity Company's electrical source and generator, while block data 5, block data 6, and block data 7 were assumed as the electrical data from three loading contacts. The ACS712 current sensor and ZMPT101B voltage sensor were used to detect each electricity from block 3-7 and the result was processed in Arduino Mega 2560 microcontroller. There were relay block 1-7 in which these blocks were assumed as the breaker and connector for the flow of electricity from the State Electricity Company, generators, Photovoltaic (PV) and wind turbines. There were also relay blocks for breakers and connectors of 3 (three) load contact blocks: legal indoor, legal outdoor, and illegal outdoor. The NRF2401+ acted as the media that received data from the 

FESPE

device in wind turbine and PV power plants. The ESP8266 block acted as the communication media for longdistance monitoring and controlling system through web media.

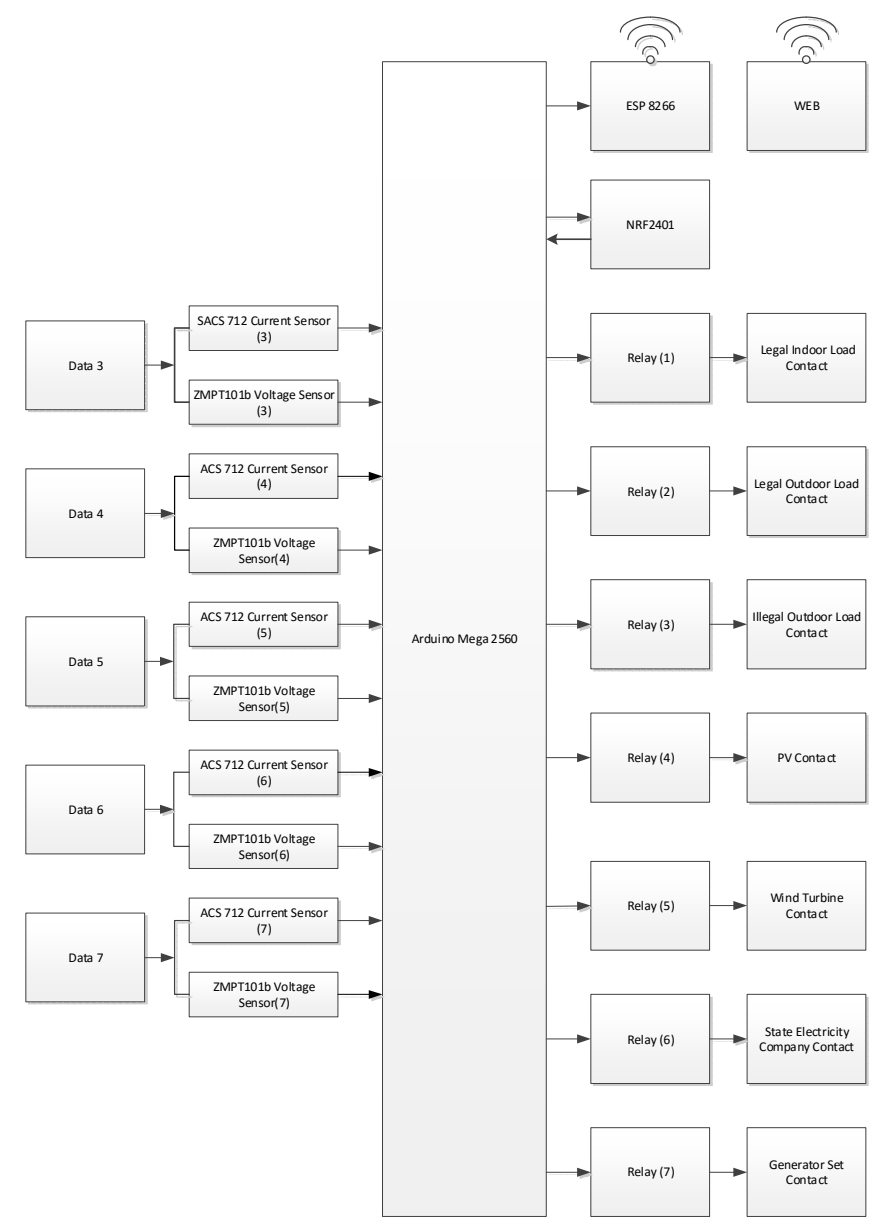

Figure 4. The Main Device

\subsection{System Flowchart}

The main system flowchart in Figure 5 explains about the performance of this monitoring and controlling system. The device had several inputs: ACS712 current sensor, ZMPT101B voltage sensor, LDR light sensor, rotary encoder rotational wind speed sensor, and DHT11temperature and humidity sensor. Each parameter measuring device was monitored through the web using the IoT. The initial step observed the value of each measurement. There was a setting for the current value on the web that was useful to set the value of the current use limit at the output load contact. The output loading contact had three load contacts. If the sensor detected current value more than the predetermined value, the controller would order the relay contact to cut the electricity. Whereas when the sensor detected the current value less than the initial setting, the relay contact would reconnect and the electricity was back again. 


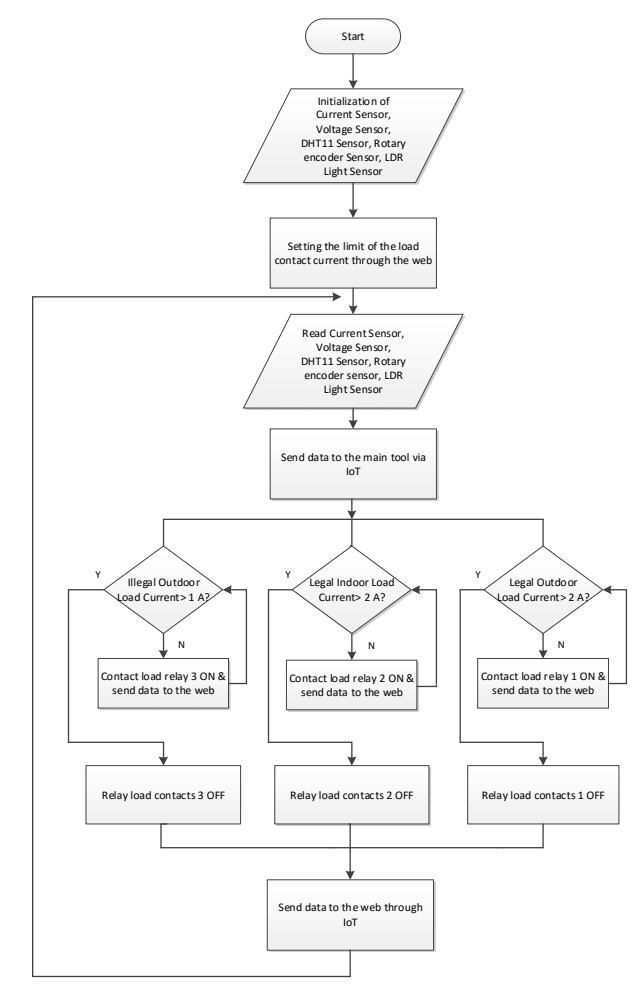

Figure 5. System Flowchart

\subsection{Device Testing}

After all, components were connected according to the designated system diagram block and the software to support the system was made; there were device testing and analysis. The steps were:

- Tested each block such as ACS712 current sensor, ZMPT101B voltage sensor, LDR light sensor input blocks. Then moved to the processing block in Arduino Mega 2560, Arduino Nano, and ESP 8266 continued to the output blocks of relay contact and NRF2401 radio frequency communication block.

- Sensor calibration.

- Combined the blocks into a system.

- Overall testing.

- Evaluated the overall testing system.

\subsection{Decision Making}

The final decision making was conducted based on the obtained data from the overall system testing. If the results followed the plan, the device met the expectation.

\section{Result}

The sensor testing of ACS712 current sensor, ZMPT101B voltage sensor, DC sensor, and LDR light sensor was sent to the web through the internet network by esp 8266 module and sending data to the web every 1 minute.

TABLE I. OVERALL SYSTEM TEST RESULTS OF MONITORING FUNCTION

\begin{tabular}{|c|c|c|c|c|c|}
\hline No & Monitored Parameter & Website & $\begin{array}{l}\text { Measuring } \\
\text { instrument }\end{array}$ & Status & Error \% \\
\hline 1 & $\begin{array}{l}\text { State Electricity } \\
\text { Company's voltage }\end{array}$ & $220 \mathrm{VAC}$ & $220 \mathrm{VAC}$ & Connected & $0 \%$ \\
\hline 2 & Generator's voltage & $222 \mathrm{VAC}$ & $220 \mathrm{VAC}$ & Connected & $0.9 \%$ \\
\hline 3 & $\begin{array}{l}\text { Solar Power Plant's } \\
\text { voltage }\end{array}$ & 21.71 VDC & $21.32 \mathrm{VDC}$ & Connected & $1.79 \%$ \\
\hline 4 & $\begin{array}{l}\text { Windmill Power Plant's } \\
\text { voltage }\end{array}$ & $0 \mathrm{VDC}$ & $0 \mathrm{VDC}$ & Not connected & $0 \%$ \\
\hline
\end{tabular}




\begin{tabular}{|c|c|c|c|c|c|}
\hline No & Monitored Parameter & Website & $\begin{array}{l}\text { Measuring } \\
\text { instrument }\end{array}$ & Status & Error \% \\
\hline 5 & $\begin{array}{l}\text { Legal Indoor Load's } \\
\text { voltage }\end{array}$ & $221 \mathrm{VAC}$ & $220 \mathrm{VAC}$ & Connected & $0.45 \%$ \\
\hline 6 & $\begin{array}{l}\text { Legal Outdoor Load's } \\
\text { voltage }\end{array}$ & $223 \mathrm{VAC}$ & $220 \mathrm{VAC}$ & Connected & $1.36 \%$ \\
\hline 7 & $\begin{array}{l}\text { Illegal Outdoor Load's } \\
\text { voltage }\end{array}$ & $221 \mathrm{VAC}$ & $220 \mathrm{VAC}$ & Connected & $0.45 \%$ \\
\hline 8 & $\begin{array}{l}\text { State Electricity } \\
\text { Company's current }\end{array}$ & $0.29 \mathrm{~A}$ & $0.30 \mathrm{~A}$ & Connected & $3.44 \%$ \\
\hline 9 & Generator's current & $0.30 \mathrm{~A}$ & $0.30 \mathrm{~A}$ & Connected & $0 \%$ \\
\hline 10 & $\begin{array}{l}\text { Solar Power Plant's } \\
\text { current }\end{array}$ & $0.43 \mathrm{~A}$ & $0.45 \mathrm{~A}$ & Connected & $4.65 \%$ \\
\hline 11 & $\begin{array}{l}\text { Windmill Power Plant's } \\
\text { current }\end{array}$ & $0 \mathrm{~A}$ & $0 \mathrm{~A}$ & Not connected & $0 \%$ \\
\hline 12 & $\begin{array}{l}\text { Legal Indoor Load's } \\
\text { current }\end{array}$ & $0.30 \mathrm{~A}$ & $0.30 \mathrm{~A}$ & Connected & $0 \%$ \\
\hline 13 & $\begin{array}{l}\text { Legal Outdoor Load's } \\
\text { current }\end{array}$ & $0.29 \mathrm{~A}$ & $0.30 \mathrm{~A}$ & Connected & $3.44 \%$ \\
\hline 14 & $\begin{array}{l}\text { Illegal Outdoor Load's } \\
\text { current }\end{array}$ & $0.29 \mathrm{~A}$ & $0.30 \mathrm{~A}$ & Connected & $3.44 \%$ \\
\hline 15 & $\begin{array}{l}\text { State Electricity } \\
\text { Company's power }\end{array}$ & $63.9 \mathrm{VA}$ & $63.9 \mathrm{VA}$ & Connected & $0 \%$ \\
\hline 16 & Generator's power & $66 \mathrm{VA}$ & $66 \mathrm{VA}$ & Connected & $0 \%$ \\
\hline 17 & $\begin{array}{l}\text { Solar Power Plant's } \\
\text { power }\end{array}$ & $9.3 \mathrm{VA}$ & $9.3 \mathrm{VA}$ & Connected & $0 \%$ \\
\hline 18 & $\begin{array}{l}\text { Windmill Power Plant's } \\
\text { power }\end{array}$ & $0 \mathrm{VA}$ & $0 \mathrm{VA}$ & Not connected & $0 \%$ \\
\hline 19 & $\begin{array}{l}\text { Legal Indoor Load's } \\
\text { power }\end{array}$ & $66 \mathrm{VA}$ & $66 \mathrm{VA}$ & Connected & $0 \%$ \\
\hline 20 & $\begin{array}{l}\text { Legal Outdoor Load's } \\
\text { power }\end{array}$ & $63.8 \mathrm{VA}$ & $63.8 \mathrm{VA}$ & Connected & $0 \%$ \\
\hline 21 & $\begin{array}{l}\text { Illegal Outdoor Load's } \\
\text { power }\end{array}$ & $63.8 \mathrm{VA}$ & $63.8 \mathrm{VA}$ & Connected & $0 \%$ \\
\hline \multicolumn{5}{|c|}{ The Average Error Value in the Current } & $2.13 \%$ \\
\hline \multicolumn{5}{|c|}{ The Average Error Value in the Voltage } & $0.7 \%$ \\
\hline \multicolumn{5}{|c|}{ The Average Error Value in the Power } & $0 \%$ \\
\hline
\end{tabular}

The comparison above shows the average error value of several obtained measurement parameters. The average value of the error results was displayed on the website. The average error value in the current parameter was $2.13 \%$, close to the results of the average error value in the current sensor test, which was $1.15 \%$. The average value of the voltage error was $0.7 \%$, close to the average value of the voltage error sensor test, which was $0.73 \%$. And the average value of the error in the power parameter was $0 \%$.

TABLE II. OVERALL SYSTEM TEST RESULTS OF CONTROLLINGFUNCTION

\begin{tabular}{|c|l|l|l|}
\hline No & Electricity Sources & Status & Response Time (s) \\
\hline 1 & State Electricity Company & ON & 0.22 \\
\cline { 3 - 4 } & & OFF & 0.25 \\
\hline 2 & Generator & ON & 0.25 \\
\cline { 3 - 4 } & & OFF & 0.23 \\
\hline 3 & Solar Power & ON & 0.22 \\
\cline { 3 - 4 } & & OFF & 0.21 \\
\hline 4 & Windmill Power & ON & 0.25 \\
\hline
\end{tabular}




\begin{tabular}{|l|c|c|}
\hline & OFF & 0.23 \\
\hline \multicolumn{2}{|l|}{ Total Response Time (s) } & 1.86 \\
\hline Average Response Time (s) & 0.23 \\
\hline
\end{tabular}

The average response time for ON-OFF action for electricity from State Electricity Company was 0.23 seconds, while in the generator was 0.24 seconds, and from the solar power plant was 0.21 seconds. The average response time for ON-OFF action for electricity from the windmill power plant was 0.24 seconds. Therefore, the average response time for the control function to regulate the transfer of 4 sources of electrical energy from the website to the main equipment through the internet network was 0.23 seconds.

TABLE III. OVERALL SYSTEM TEST RESULTS FOR LOAD CONTACT CONTROL

\begin{tabular}{|l|c|l|c|}
\hline \multirow{2}{*}{ No } & Load Contact & Status & $\begin{array}{c}\text { Response } \\
\text { Time (s) }\end{array}$ \\
\hline \multirow{2}{*}{1} & \multirow{2}{*}{ Legal Indoor } & ON & 0.23 \\
\cline { 3 - 4 } & & OFF & 0.27 \\
\hline \multirow{2}{*}{2} & \multirow{2}{*}{ Legal Outdoor } & ON & 0.21 \\
\cline { 3 - 4 } & & OFF & 0.23 \\
\hline \multirow{2}{*}{3} & \multirow{2}{*}{ Illegal Outdoor } & ON & 0.22 \\
\cline { 3 - 4 } & OFF & 0.25 \\
\hline \multicolumn{2}{|c|}{ Total Response Time (s) } & 1.41 \\
\hline \multicolumn{2}{|c|}{ Average Response Time (s) } \\
\hline
\end{tabular}

The average response time for ON-OFF action for electricity from the legal indoor was 0.25 seconds, the average response time for ON-OFF action for electricity from legal outdoor was 0.22 seconds, the average response time for $\mathrm{ON}-\mathrm{OFF}$ action for electricity from illegal outdoor load was 0.23 second. Therefore, the average response time for the control function to regulate the transfer of 3 output contacts from the website to the main equipment through the internet network was 0.23 seconds.

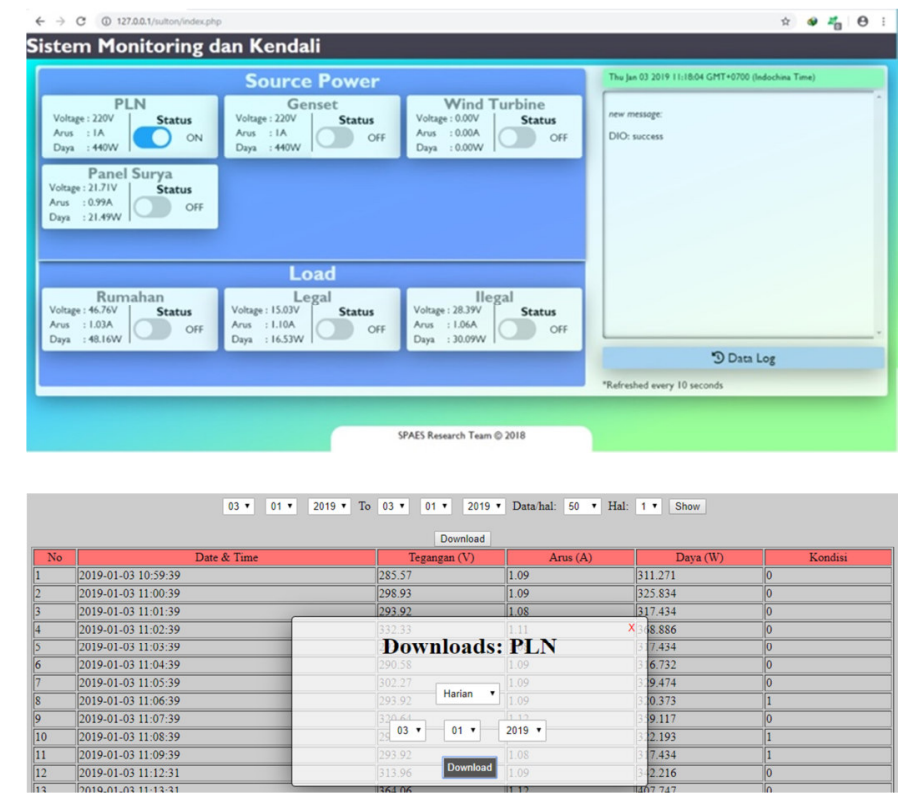

Figure 6. Monitoring and Controlling Display and Data Logger Display.

\section{Conclusion}

The monitoring parameters using the implementation of the IoT obtained a result in a comparison between the average error value of the device and the average error value of the competent measuring instrument. The average error value on the current parameter was $2.13 \%$. The average error value of the voltage parameter was 
$0.7 \%$. Moreover, the average value of the power parameter was $0 \%$. The response time in the control process using the IoT was taken from four input contacts and three output contacts with the average response time from the website to the primary device through the internet were 0.23 seconds

\section{References}

[1] A. Sagastume Gutiérrez, M. Balbis Morejón, J. J. Cabello Eras, M. Cabello Ulloa, F. J. Rey Martínez, and J. G. Rueda-Bayona, "Data supporting the forecast of electricity generation capacity from nonconventional renewable energy sources in Colombia," Data Brief, vol. 28, p. 104949, Feb. 2020, doi: 10.1016/j.dib.2019.104949.

[2] S. A. A. Shah, "Feasibility study of renewable energy sources for developing the hydrogen economy in Pakistan," Int. J. Hydrog. Energy, p. S0360319919335530, Oct. 2019, doi: 10.1016/j.ijhydene.2019.09.153.

[3] R. Poudyal, P. Loskot, R. Nepal, R. Parajuli, and S. K. Khadka, "Mitigating the current energy crisis in Nepal with renewable energy sources,” Renew. Sustain. Energy Rev., vol. 116, p. 109388, Dec. 2019, doi: 10.1016/j.rser.2019.109388.

[4] M. Talaat, A. S. Alsayyari, A. Alblawi, and A. Y. Hatata, "Hybrid-Cloud-Based Data Processing for Power System Monitoring in Smart Grids," Sustain. Cities Soc., p. 102049, Jan. 2020, doi: 10.1016/j.scs.2020.102049.

[5] O. Cortes-Robles, E. Barocio, J. Segundo, D. Guillen, and J. C. Olivares-Galvan, "A qualitativequantitative hybrid approach for power quality disturbance monitoring on microgrid systems," Measurement, vol. 154, p. 107453, Mar. 2020, doi: 10.1016/j.measurement.2019.107453.

[6] J. H. Min, D.-W. Kim, and C.-Y. Park, "Demonstration of the validity of the early warning in online monitoring system for nuclear power plants," Nucl. Eng. Des., vol. 349, pp. 56-62, Aug. 2019, doi: 10.1016/j.nucengdes.2019.04.028.

[7] O. Yildirim, B. Eristi, H. Eristi, S. Unal, Y. Erol, and Y. Demir, "FPGA-based online power quality monitoring system for electrical distribution network," Measurement, vol. 121, pp. 109-121, Jun. 2018, doi: 10.1016/j.measurement.2018.02.058.

[8] E. F. Ferreira and J. D. Barros, "Faults Monitoring System in the Electric Power Grid of Medium Voltage," Procedia Comput. Sci., vol. 130, pp. 696-703, 2018, doi: 10.1016/j.procs.2018.04.123.

[9] A. Girgin, M. Bilmez, H. Y. Amin, and T. C. Karalar, "A silicon Hall sensor SoC for current sensors," Microelectron. J., vol. 90, pp. 12-18, Aug. 2019, doi: 10.1016/j.mejo.2019.04.020.

[10] Z. Ou et al., "Self-biased magnetoelectric current sensor based on $\mathrm{SrFe} 12 \mathrm{O} 19 / \mathrm{FeCuNbSiB} / \mathrm{PZT}$ composite," Sens. Actuators Phys., vol. 290, pp. 8-13, May 2019, doi: 10.1016/j.sna.2019.03.008.

[11] G. Huang, E. F. Fukushima, J. She, C. Zhang, and J. He, "Estimation of sensor faults and unknown disturbance in current measurement circuits for PMSM drive system," Measurement, vol. 137, pp. 580 587, Apr. 2019, doi: 10.1016/j.measurement.2019.01.076.

[12] R. Zhang et al., "A New Environmental Monitoring System Based on WiFi Technology," Procedia CIRP, vol. 83, pp. 394-397, 2019, doi: 10.1016/j.procir.2019.04.088.

[13] R. Muhendra, A. Rinaldi, M. Budiman, and Khairurrijal, "Development of WiFi Mesh Infrastructure for Internet of Things Applications," Procedia Eng., vol. 170, pp. 332-337, 2017, doi: 10.1016/j.proeng.2017.03.045.

[14] B. Jain, G. Brar, J. Malhotra, S. Rani, and S. H. Ahmed, "A cross layer protocol for traffic management in Social Internet of Vehicles,” Future Gener. Comput. Syst., vol. 82, pp. 707-714, May 2018, doi: 10.1016/j.future.2017.11.019. 